\title{
Investigation of the Dome-Like and Arched Structures with Sustainable Masonry in Sassanid Architecture (Case Study: Mushkan Fire Temple)
}

\author{
Mohamad Masoud Ghiabi \\ Department of Architecture, Faculty of Engineering, Technical University of Tehran, Tehran, Iran
}

Email address:

mohamadmasoudghiabi@gmail.com

\section{To cite this article:}

Mohamad Masoud Ghiabi. Investigation of the Dome-Like and Arched Structures with Sustainable Masonry in Sassanid Architecture (Case Study: Mushkan Fire Temple). Landscape Architecture and Regional Planning. Vol. 6, No. 3, 2021, pp. 46-55.

doi: 10.11648/j.larp.20210603.11

Received: February 4, 2021; Accepted: March 17, 2021; Published: August 24, 2021

\begin{abstract}
Architecture and structures' sustainability date back to several thousand years ago in Iran. Iranian architecture has created countless historical buildings in a vast territory in the course of centuries and it has been able to solve complex structural problems and create magnificent architectural masterpieces. The structures of the roofs, domes and mosques and other edifices are all signs of the proper interaction between the architectural principles and structural behavior therein. Iran's Islamic architecture is the natural continuation of the Sassanid Era's architecture and the recognition and study of it can pave the way for us to identify the Islamic period's architecture and its various aspects. Sassanids' architecture was highly capable of erecting vaulted and domelike covers on square substructures and their method of constructing domes was spread and continued in various regions. Moreover, the effect of religion in the architectural designing of this period and the existence of Zoroastrianism caused the creation of different fire temples the remnants of which have been found in Fars, Kermanshah, Ilam, Kerman, Khorasan and other provinces. The present study investigates Mushkan fire temple as a case study in Chardavol County. Therefore, the present study has been conducted with the objective of investigating the structural stability and method of the construction of four-dome and vaulted structures in Sassanids' era through the use of library resources and documents and also by relying on a descriptiveanalytical method and field studies. The results obtained from the present study indicated that the use of sustainable masonry, including stone, lime-ash or sand plaster and gypsum, as well as methods of constructing four-dome structures and vaults and dissipation of force on four pillars are amongst the reasons for the structural stability in Mushkan Fire Temple.
\end{abstract}

Keywords: Structural Stability, Vault, Dome, Sassanids, Mushkan Fire Temple

\section{Introduction}

Sassanid empire has been based on a unit ideology and religion and it endeavored to influence all the aspects of human life. In Zoroastrianism, the four vital elements (water, fire, wind and soil) are consecrated and sullying of them is a $\sin$. In between, fire is given more importance because it has had a role of purification. Sassanid kingship is the first dynasty in the history of ancient Iran that authenticated Zoroastrianism in its government and founded a religious sovereignty. Zoroastrianism has had a special effect on the Sassanid era's art and architecture; during Sassanids' period, besides the construction of important and great fire temples, a large number of four-dome structures were built and religious ceremonies were held in them. In the historical texts remained from this period, including Shapour I's inscription in Kaaba of Zoroaster, Mihr Narseh Epigraphs and Kertir Inscriptions. the news and/or the commands about the construction of four-dome structures by the kings and/or chiefs are repeatedly encountered which are reflective of the important position of the fire temples and utility buildings' constructions [1]. Amongst the religious fire temple-like buildings from Sassanid Era are the domes and vaults the remnants of which have been found in Fars, Kermanshah, Ilam, Kerman, Khorasan and other provinces.

Since the past, Iranians considered and used the dome in 
their buildings as a mediatory component separating from the ground and connecting to the sky and they are even the first tribes that offered innovative ways for promoting and constructing this element on a four-cornered substructure; this identity-bestowing element was frequently used in buildings like mosques and mortuaries. The dome construction dates back in Iran to the third millennium BC. Since then, Iranian architecture has created various kinds of structures with the best domelike shapes through the use of traditional methods. Since the dome-construction method in Iran has always been conducted by the use of exact mathematical order in the formation and building and through the application of correct methods, there are still many of them persisting [2]. During the Sassanid era, the dome-building becomes so common and prevalent and evolved that the dome cover has been since applied as a pattern and a general guideline for its construction aesthetics and stability.

The traditional architects have planned the functional attributes of the building elements so that the latent concepts can be revealed. Therefore, the revealing of the truths and veracity of the constructional materials' structural behavior seems as if it is enlivening them and making them capable of worshipping the God. Due to the same reason, geometry is the common language between the architecture and the structure so that a proper dialectic can be made in between. As a conforming survey between the form, staticity and relations and proportions, geometry has always been a principle holding true in the interaction between the structure and Iran's traditional architecture [3].

Dome and vault can be investigated in Iranian buildings from various perspectives like the method of genesis, method of construction and shape differences with those of the other countries as well as the structural system and the process taken for their implementation. However, the present study aims at investigating Sassanid Era's domes and vaults thereby to reveal the construction methods as well as the structural strength and stability and also their staticity style.

\section{Study Method}

The present article is an applied research in terms of goal and it is a library research and descriptive-analytical study in terms of the data gathering method. This way and through the use of the cognitive grounds and the results obtained from the field studies and also by gathering information through documentary studies, the present article seeks achievement of development in applied knowledge and obtainment of a practical goal. The present research paper's goal and intention is producing knowledge and awareness in the area of investigating the dome and vault structures from the Sassanid Era as well as the methods of their construction and sustainability. The present article seminally studies the methods of dome and vault structures' construction via collecting pictorial documents and scientific evidence and eventually evaluates the stability and staticity style of these structures. In the end and through the use of the field studies, the staticity and construction method of Siah Gol FireTemple will be dealt with.

\section{Four-Dome Structure Defined}

Four-dome is a term conveying several meanings and it is used to name a sort of building, tent, hat and several villages; there are also ironical meanings derived thereof. The dictionaries define the four-dome buildings in the following words: a dome or vault laid on four pillars and columns; there is an arch on each side of the dome and each of the four domes is laid on two foundations and columns; the dome or vault is covered by roofs and ceilings on the outside and inside [Dehkhoda, 1993, under the term "four-dome"]. It is a roof or dome laid on four foundations and featuring four open sides [Mo'ein, 1984, under the term "four-dome"].

Four-domes are famous with names like fire-temple, fireplace, synagogue, castle, palace and sanctuary. Each of these names has been drawn on the nature and content ascribed to such edifices.

\section{Dome and Vault in Sassanid Era}

Despite the long life of Sassanid Dynasty, there are not remained many architectural artworks from this period; thus, there are problems in the study of this period's architectural aspects, dating and stylistics [4]. Zoroastrianism has been the formal creed in Sassanid Era and the buildings related to this religion enjoyed a significant stance. The main building of the temples was in the form of four-dome structures underneath which fire has been flaming and it has been vividly observable by the believers in the course of the religious ceremonies from the four spans and there have always been complexes wherein fire was maintained inside them in other occasions.

The general studies performed about the well-known religious buildings in the Sassanid Era indicate that the religious buildings of this period have mostly had four-dome plans. Shipman has divided the Sassanid Era's four-domes into two primary groups following his researches about the four-domes: the first group includes the four-domes with large structures [Solomon's throne] and the second group includes singular four-domes to which fire temples or other ancillary rooms have been occasionally added [Niasar Fire Temple] [5].

From the architectural perspectives, the Sassanid Era's religious buildings can be divided into three general sets:

1) Religious complexes the central core of which is formed by a vaulted four-dome structure and a covered corridor in its periphery with spaces serving various functions falling in the periphery of this section.

2) Free and independent fire-temples and fire-places that include a vaulted four-dome and a covered corridor in its periphery.

3) Vaulted and independent four-domes that have four wide and open spans towards the periphery with their interior spaces being visible from all sides. 
In regard of the function and dating of the third group, there are numerous discussions put forth. According to Huff, the term "four-dome" actually conveys a four-cornered building that is composed of four arches in between the corner piers or it only ends in four walls with the middle space being covered by quenches. As believed by Andrea Godard and K. Erdmann, these buildings are the relics of the Sassanid Era's fire temples that are spread in umbrella form on the holy fire which has been visible from inside the spans of the four-dome even from a long distance. In spite of this idea, the evidence shows that the ancient Iranian temples have been completely closed in respect to the exterior space [6]. Absence of specific stylistics and dating has caused any type of independent four-dome structure lacking specified dating document to be attributed as a fire temple to this period.

The Persian Sassanid architecture has more likely inherited the Mesopotamian dome-building architecture. The ruins of Ardashir Babakan's palace and Qal'eh Dokhtar [Firouz Abad] castle in Fars province were reconstructed by Ardashir I and domes were later on placed on them during the Sassanid Era. Dome-building becomes so prevalent and evolved in Sassanid Era that dome-like covers have been used since then as a pattern and general guideline. The domebuilding method in the Sassanid era is carried out with such an exact mathematical order in formation and construction through the use of correct methods that the buildings can well resist all the compressive and thrusting forces without any need for braces and internal structures and casts.

\section{Sassanid Era's Dome-Like Covers}

Domes date back to long ago in the world's architecture but all the prior domes were laid on a round foundation and it was the Sassanid architects who resolved the problem of erecting dome on a four-cornered surface. Unlike in Islamic period that the dome was placed on a square, round and polygonal substructure, Sassanids' domes were laid only on square structure by the use of rubbles, carved stone and brick. Erecting dome by the aid of cornering on fourcornered surfaces was first appeared in Ardashir I and Qal'eh Dokhtar Palaces and its general method remained almost unchanged till the end of Sassanid Period and left a decisive effect on the Islamic architecture. The diversity of the cornering forms in this period brings testimony to the daily increasing efforts made by the architects for the achievement of their desired shapes. In the early stages, the dome's springing line is still not completely circular rather it has been rounded in an octagonal form. In more recent samples [in Qasr-e-Shirin], it approaches its perfect geometrical shape and it is finally in the Islamic period that this problem is completely resolved [6].

In Iranian architecture, the domes were built without molds but the order governing dome construction has been so exact that the domes show the best resistance against various kinds of seismic and thrusting forces. Amongst the prominent issues that should be pointed out about the forms of the dome structures is the staticity feature of such buildings. The domes that feature a round geometrical shape with bilateral curvature according to their definition transmit the weight load and other forces essentially by the mechanism of membrane force to the supports. The geometrical form of the domes features this property that lowest tensile stress is created in such forms. Thus, the domes' construction is completely feasible even with the constructional materials [mud, brick and stone] that cannot tolerate the bending forces. From the perspective of the building forms' perfection, the dome forms have ability and superiority over the frame-like structural forms and even arched building forms. Amongst the other advantages of the arched roofs and domes is that the wind passes over the concave surfaces more easily and causes lower erosion and destruction [7].

Andrea Godard believes that the Sassanid architects used to curve the lower sections of the domes that were rendered feasible with or without cornering and/or small conical roofs to erect domes [Godard, 1992, pp. 19-24]. In order to construct a number of domes, Sassanid architects used gypsum ribs. In this method, after the dome's springing line was prepared, a plan of the dome's cross-section was drawn on the ground and ribs were prepared accordingly through the use of cane segments and gypsum mortars and they were placed in certain distances on the dome's springing line in such a way that their heads were tied together and their foundations were braced inside the last row of the springing line. After this stage, the main body of the dome was consistently filled with stone in the distance between and periphery of the ribs [8].

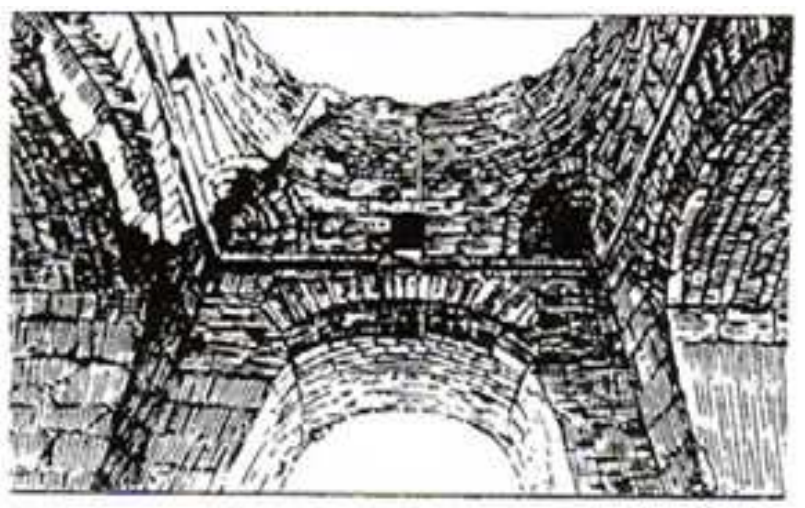

Figure 1. Method of covering Niasar Four-Dome by gypsum ribs.

\section{Arched Covers in Sassanid Period}

One of the important elements and indices of Sassanid architecture is the vast and, occasionally, memorial use of the arched structures and covers. Sassanids' technique of arch construction is substantially relying on the special quality of the gypsum mortar which hardens fast and allowed the construction of the arch without the use of molds. Semicircular arches are the most common vaults that were masterfully worked and only needed a supportive back wall or a thin strip of cast for the first row with the next rows laid attached thereto. Despite being advanced, this method prevents geometry-based building construction [9]. 


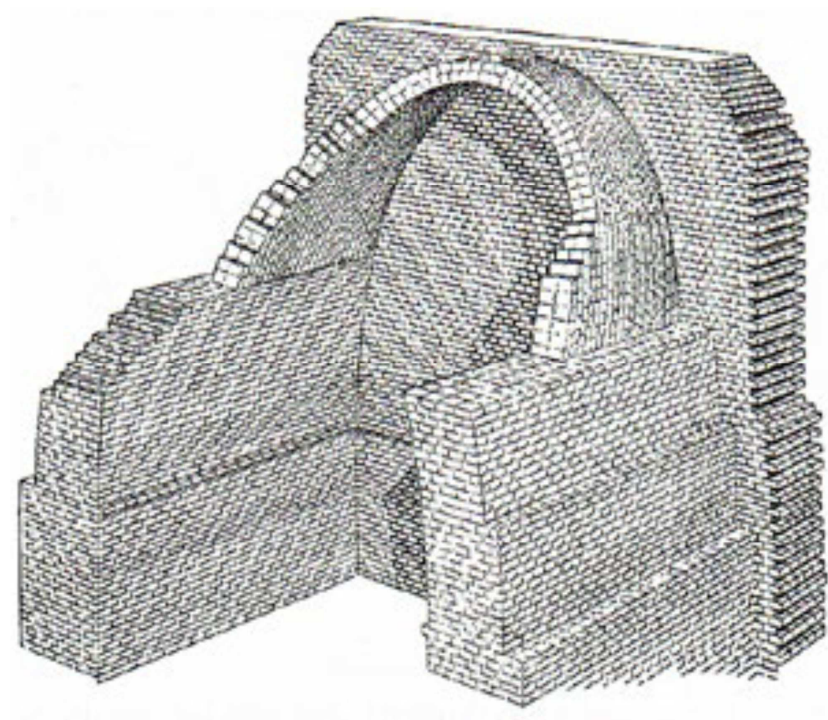

Figure 2. Schematic view of barrel arch construction [without the use of cast] [10].

Sassanid Era's arches and arched roofs can be categorized in terms of cross-section and shape into semi-circular and semi-oval kinds though cases of horseshoe and sharp gothic arches have also been identified for this period. In this method, a thin layer of stone and gypsum mortar is seminally put on the scaffold and, then, when the mortar hardened, this layer plays the role of the roof-working scaffold and cast for the placement of the stone masses and real mortar. In this method, a relatively light roof-working scaffold was needed and it was usually made to the height of the springing line on the load-bearing wall. Resultantly, the barrel vault acquired a special shape which was unique realized as specific to Sassanid period. The diameter of the arch's span in this method was larger than the breadth of the room or doorway. Therefore, the springing line of the arch was placed a little indentation in respect to the lower walls. In this method, the cross-sections of the roofs were semi-circular [11].

Another type of the arches was constructed without roofworking scaffold and featured a semi-oval plan. In this method, the architects made the roofs and arches inclined towards inside and subsequently covered the upper span with vertical rows for constructing them on large spaces and for reducing the span width through creation of a mild curvature in the springing line's walls. Therefore, the semi-oval plan of the Sassanid Era's arches is not the result of considering solidarity and stability but stemming from the practical process of the building construction. The huge cover of Taghe-Kasra Palace is the most distinct example of this type.
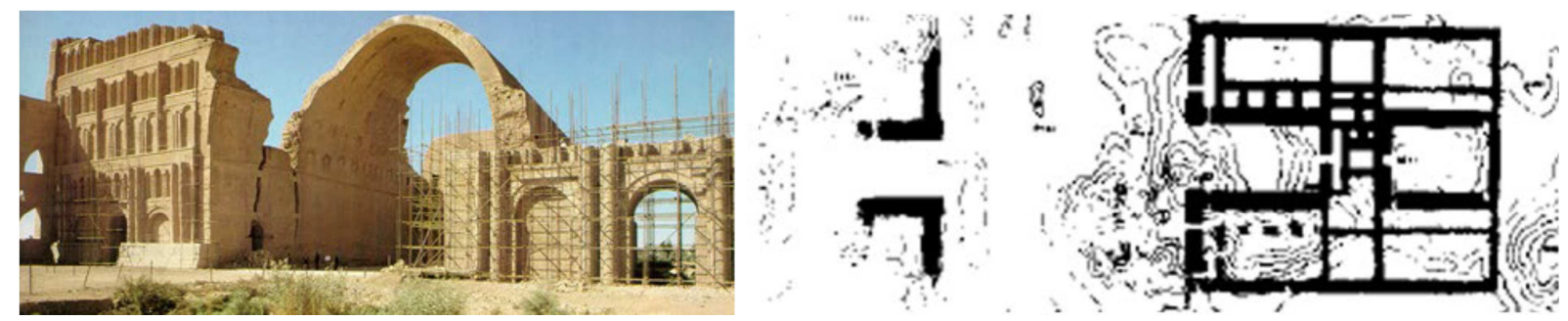

Figure 3. Ctesiphon, Taq-e-Kasra; map and current status [12].

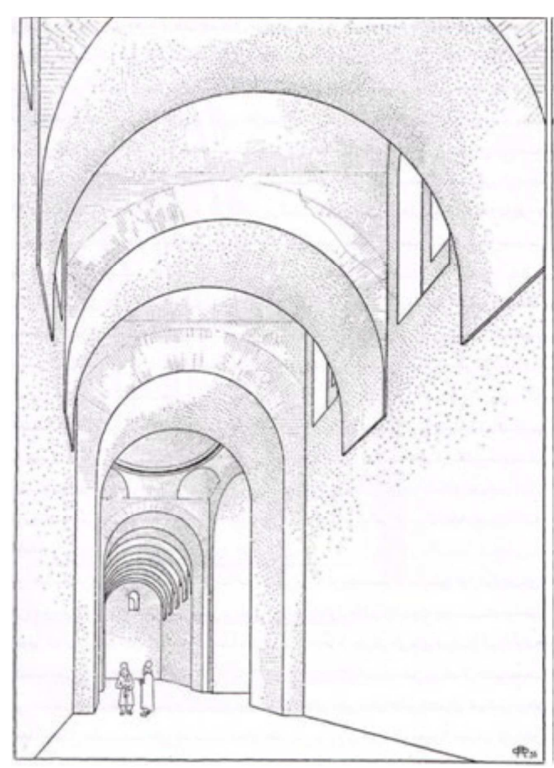

Figure 4. Karkheh Porch, intersecting wagon arches [15].

Another kind of Sassanid Era's arch or roof is horseshoelike in shape which becomes later on prevalent during the early Islamic periods. This type of arch first appeared in Firouz Abad Palace [13].

Amongst the other kinds of arches seen in Sassanids' architecture are the primitive examples of the roof and rib covers as a sort of combined covering consisted of a series of roof and rib placed along one another. In this method, the roof's thrust is distributed on certain spots of more robust arches instead of putting pressure on the lateral walls. This method allows the architect install windows in the distance between two arches. This method was continued in the Islamic architecture [Tajvidi, 1984, p. 18]. The outstanding example of this roof can be seen in Karkheh Porch. Here, the barrel roof that was commonly implemented in Sassanid Era has not been constructed and five large arches or ribs have been built instead in the width of the space with their middle distances being filled with some arches [14].

Investigation of the method of fixing the arch and dome: From the perspective of staticity, arched forms, including the domes and roofs, are forms wherein the weight load and other forces are transmitted essentially based on membrane force mechanism [and a little bending force]. Therefore, arched forms are more technical and they are closer to the curve of forces as the perfect curve of the building form and 
possess superiorities to the frame-like forms [16].

Brick-laid arches used for covering the doorways are formed by joining the wedge-like brick streaks each of which keep the elements alongside one another by their own pressure. In general, the loads imposed from above are transmitted by the arch's shoulder to the ground through the supports. It has to be noted that the force transmitted in springing line will be per se divided into two components. The arch's balance is closely associated with the base or pier and the rotational torque imposed by the loads transmitted by the arch's shoulder.

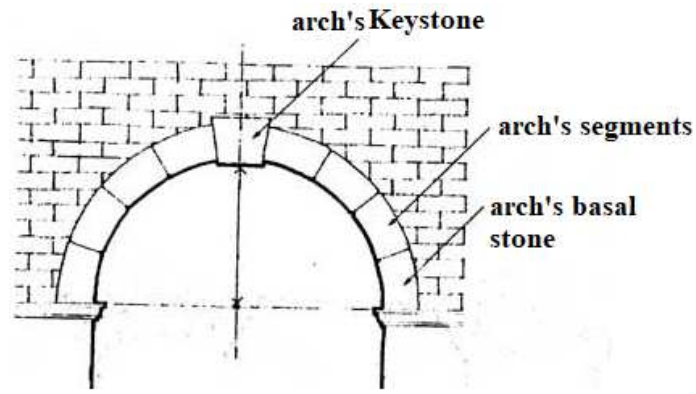

Figure 5. Segments of an arch with constructional materials.

The followings are arch parts wherein the effect of the forces is more accentuated:

1) Haunch angle: in this point, the first gaps and failures of the arch's curve are observed. In Iranian arches, this angle is about 22.50 degrees.

2) Spandrel: the space between two side-by-side arches and it transfers the load from the side of the wall above the arch hence it is responsible for balancing the whole structure. A part of the thrust force imposed in an inclined manner on the shoulder of the arch is combined with the weight of this section and causes the balance of the arch in some occasions.

3) Pier: it is the element perpendicular to the ground and it is responsible for transmitting the forces imposed by the arch to the ground. It is usually $1.3 \mathrm{~m}$ in thickness. The sum of the forces imposed on the arch should pass through it otherwise the structure would become imbalanced.

4) Base or support: if the cross-section of the arch's base is divided into three parts, the middle section is $1.3 \mathrm{~m}$ in thickness and it is called the base's thick section.

(a)

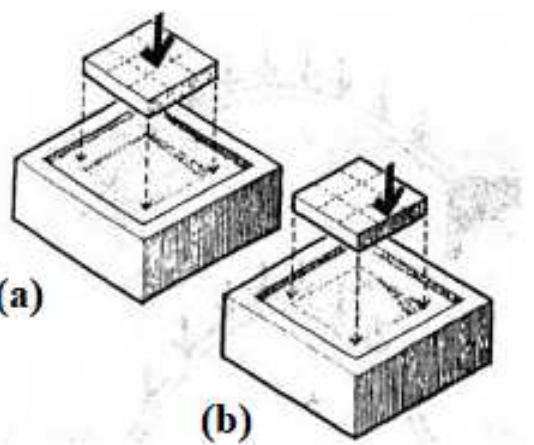

Figure 6. Tracking details.
The model of the middle one-third rule: a] the force imposed on the foundation center passes through the center and its result is the dissipation of the force onto the support soil; b] the force imposed on the middle one-third of the foundation with its result being a tensile force on parts of the support soil. This general rule prevents the tensile force from being expanded and it creates a thrust line inside the center in the compressible structures [like arches].

The followings are amongst the preconditions of balance:

1) The pressure curve should fall inside the arch.

2) In every cross-section of the arch, the tensile force should be prevented from creation. This means that the output of the forces imposed on each cross-section should fall inside the 1.3-meter thick crown of the arch.

In case that compressive forces are imposed on the arches, they are transmitted from the arch's sharp tip to the bases on two sides of the arch. These forces that are the product of the beam and wall's weights on the arches will be decomposed into two indicators, namely horizontal and perpendicular, in the support. These two forces that are originated from the main force will be dissipated to the ground through the wall and lateral columns.

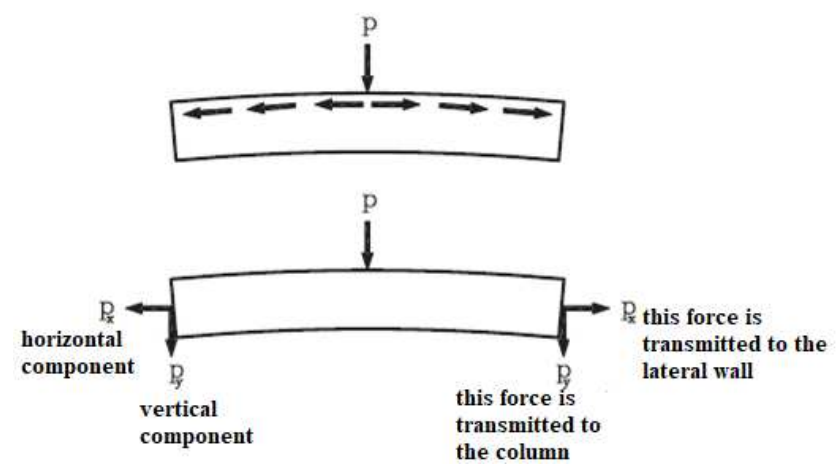

Figure 7. Stretching and bending in the arch.

\section{Force Transmission in Arches}

\subsection{Structural and Static Behavior in Dome}

After the introducing of the arched roofs and the evolution stages of the beams, the arch form is rotated in a 3D space and creates the dome which is a sort of shell and it possesses a distinct structural behavior in contrast to the arched roofs in this regard in such a way that it transmits the imposed loads more through the membrane forces [forces on plane] and the moment buckling is very limited therein and this is a reason for the low thickness of the dome in contrast to the arch's beams; thus, the structural behavior of this shell [membrane] is influenced by its geometrical characteristics. The other strong point of the dome [shell] is that since the loads imposed on a vast part of the structure is of stress [compressive or tensile] type, use has been appropriately made of constructional materials in the dome that cannot tolerate the tensile forces but keep the whole structure balanced and upright.

As it was mentioned, dome is a sort of shell that is 
symmetrical in respect to its axis. Thus, the stresses caused by the forces imposed by the structure's weight and others are uniformly distributed on the path of the compressive stresses' meridians and exerting a constant tolerable force on the whole structure [17].

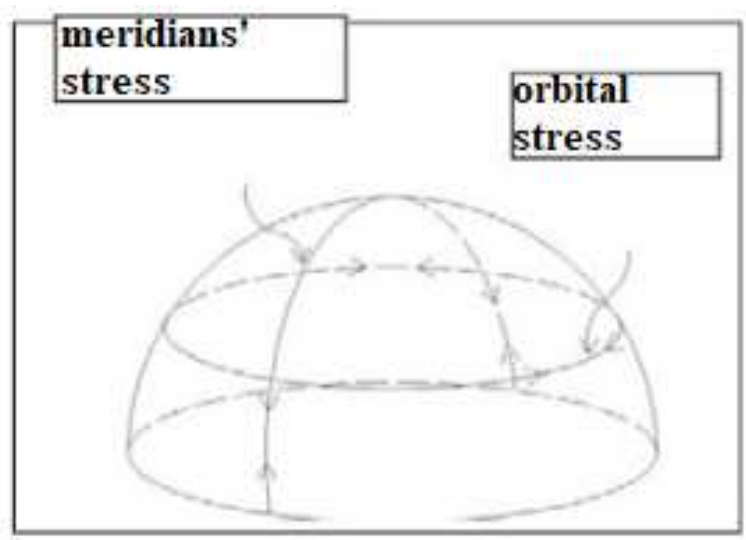

Figure 8. Arc structure.

Various Kinds of Membrane Stress on Dome

It is worth mentioning that every dome has been considered as consisted of a number of meridian and orbital elements so that the topic can be more easily perceived; in fact, they are called the cross-sections tolerating the stresses. Now, in order to explicate the performance of the meridians and orbits, let's assume a dome with a relatively high creep and subject to its own weight loads. The imposed forces can be analyzed through changing the output image.

As it is observed, the upper section of the dome is flat and the lower section is open with the points on the upper section moving inward as a result of the loads' effect but the points on the lower section moving outward and away from the axis. Based thereon, the orbits are shortened in the upper section of the dome and cause the creation of compressive stress therein whereas the orbits on the lower section of the dome are stretched and subjected to the effect of the tensile stresses in such a way that such an orbit which is in a 52degree angle in respect to the main axis undergoes changes in a dome as a result of the transmission of the meridian force and this same issue [pulling and pushing of the orbits] causes the coordination or uniform [string-like] behavior of the meridians [18].

\subsection{Building's Geographical Position}

Mushkan Fire Temple is located within a 25-kilometer from the city of Chardavol in Sarableh District and within a three-kilometer distance from Sarableh City and in Mushkan Village in the vicinity of Khorram Kouh Fortress. This fire temple was discovered in 1970 by Andenberg, a Belgic archaeologist. It has been constructed in the middle of a small plain whereon the residential houses of the region's dwellers had been existent somewhere near the fire temple; there are fertile and alluvial lands near the fire temple and they might have been possibly dedicated thereto as it has been a quite common tradition then.
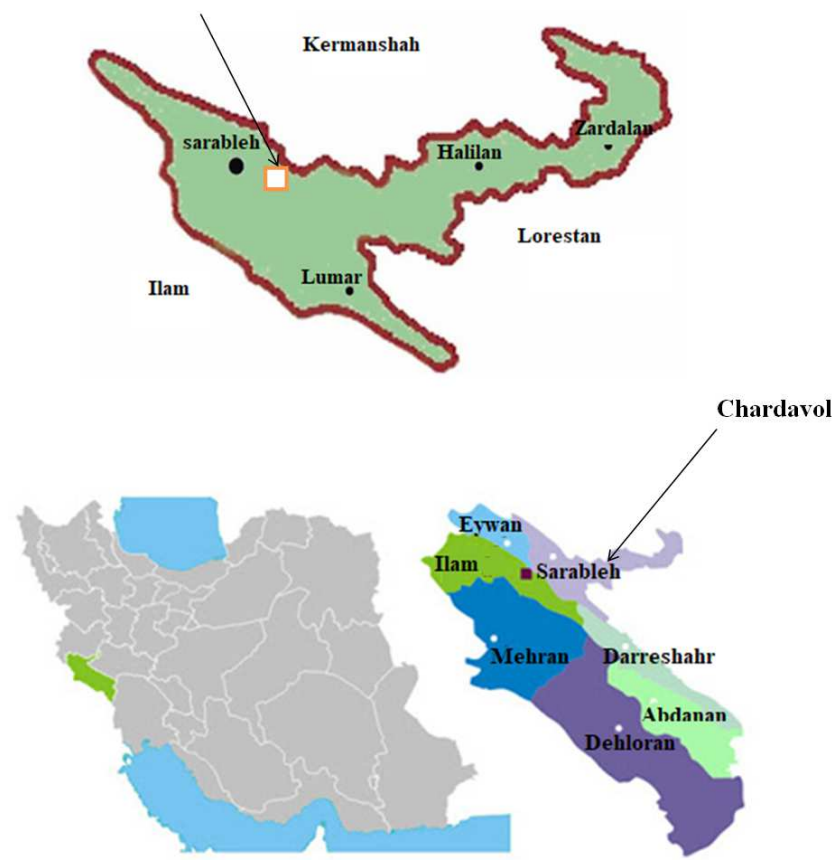

Figure 9. Location of the relevant site.
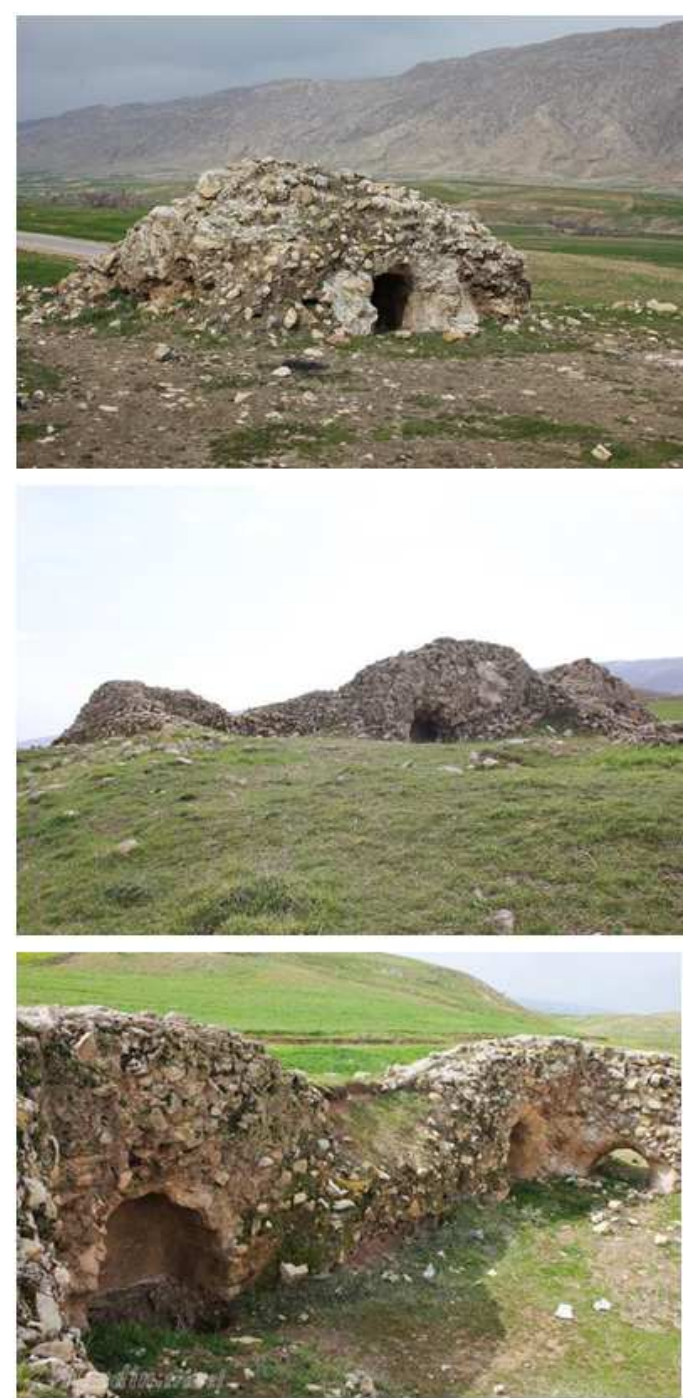

Figure 10. Images of Mushkan Fire Temple. 


\section{Geographical Position of Chardavol County in the East of Ilam Province and Mushkan Fire Temple}

The periphery of this building is surrounded by a yard but it is currently destroyed due to natural and non-natural factors. The building's architectural type belongs to Sassanid Era. In addition, the existence of a yard surrounding the fire temple which is, of course, now for years that it has been destroyed as a result of erosion and negligence reflects the Sassanid Era's architectural style. One of the other properties of the fire temple is that it was used during Sassanid Era as a religious place with four gates opening towards four main directions. In this regard, Mushkan Fire Temple is very much similar to Siah Gol Fire Temple.

The fire temple is positioned on a small plain whereon there have possibly been many residential houses. The fertile and alluvial lands in the periphery of the fire temple have been most likely endowed thereto. 1

Fire Temple's Plan

This historical building possesses a square plan, $5 \times 5$ in dimensions and about $10 \mathrm{~m}$ in height with walls being one meter in diameter; it also has a fireplace and there are holes in the upper section that might have been serving as a smoke chimney.

In this building, the method of constructing the piers and combining their structures is similar to many of Sassanid Era's four-domes, including Bazeh Hour Four-Dome, Farashband Four-Dome, Chen Jiyeh Four-Dome in Ilam, Mil Mileh Geh Four-Dome in Kermanshah [19], Mulab FourDome in Abdanan and Tagh Rostam Four-Dome in Shirvan and Chardavol. In these buildings, the small and large and irregular and shapeless rubbles have been put alongside each other in a special order by the use of gypsum mortar [20].

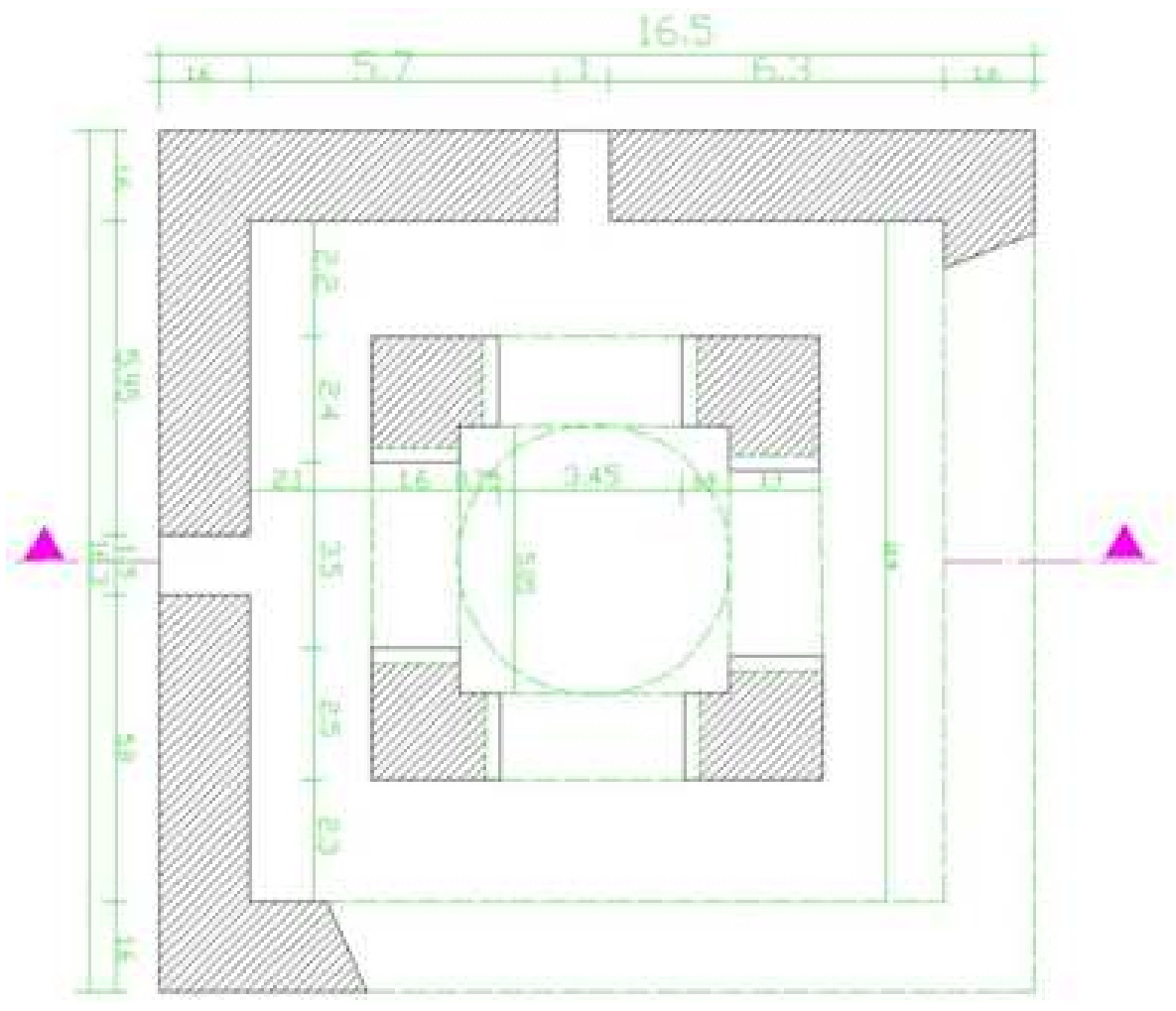

Figure 11. Plan of Mushkan Fire Temple [source: website of Ilam Province's cultural heritage organization].

Based on the recognition we have attained about the religious architecture of Sassanid era, the most important index for the attribution of the four-domes to the fire temple is the existence of a circumambulation hall in the periphery of these architectural works. Mushkan Four-Dome has a central circumambulation hall and a lot of rooms in the periphery thereof; the fireplace has been more likely in this same central hall.

Apart from the knowledge about the building's nature and use, the recognition of the architectural style and pattern used in this complex was another of the present study's goals. Rudolf Neumann followed the pattern that had been posited by Andrea Godard [1938] and Curt Erdmann [1941] for the archaeological fire temples; in this pattern, room A of Solomon's Throne was considered as the fireplace, i.e. a place for keeping the holy fire going. Although room A was not exposed to the view of the general public, it was attended by the worshippers who gathered around therein as well as in the adjacent corridors and halls [21].

In between, Gerd Gurp made efforts to offer the pattern used in the archaeological fire temples. He has proposed three types of fire temples' plans that have been used up to now [22]. Agyari is the most common example comprised of a perpendicular building in the center and a square room in the dome and it was called Adurian and surrounded by a corridor. On the other side, there was a second room that 
was called Dar-e-Mehr or Yazsin-Gah. This section was directly connected to Adurian and it was occasionally separated from it.

The second type of the fire temples was Adurian which was a square room with a dome above and a peripheral corridor; sometimes, it was also a separate room with a dome and positioned in a large yard but it lacked Yazsin-Gah.

The third type is Dar-e-Mehr that was composed of one or several Yazsin-Gah and, of course, no Adurian.

Dietrich Huff has divided the four-dome buildings into three groups in terms of the type and plan details; the first group includes the separate square four-domes that lack the corner columns and the connective arches but having erect and thin walls with three or four entrances. The second group includes the four-domes with corner columns and arches; in between them, there are wings wherein the central domecovered room is surrounded by a narrow corridor. The third group, as well, which is rather rare possesses components like the four-dome samples of the second group with the difference being that they have been surrounded by rooms and chambers and so forth instead of a round circumambulation corridor in the central part [23].

\section{Structural Stability in Mushkan Fire Temple}

One of the solutions used by Iranian architects for reaching structural stability has been the invention of the new forms that should cover the larger spans and simultaneously minimize the bending and tensile forces created in the structure. The invention of arches has been the product of such a mindset.

As it was mentioned before, the arches transmit the forces to the springing line hence the supports and bases when being subjected to the vertical or horizontal loading and the arches have the best shape for dissipating the vertical forces in case of being subjected to the forces perpendicularly imposed on the middle of them. The required span can be implemented by the use of simple masonry through the selection of the intended curve. In the arches, every section and/or every unit width of the arch acts independently and it does not depend on the other sections of the arch and it works as an independent beam in practice if the springing lines stay balanced and static.

As it is observed in the cross-section of Mushkan fire temple, the use of large span has enabled the minimization of the bending and tensile forces with the imposed pressures being transferred to the springing lines through the arch's stretch.

Additionally, the arch used in Mushkan Fire Temple is of four-dome type. This type of dome is formed by the intersection of two barrel arches like Audrina arch with the difference being that the four edges of the arch are laid on four points instead of on four surfaces. One of the reasons for the stability in Mushkan Fire Temple is the use of this same kind of arch.
The load-bearing part of the four-part arches is comprised of four arches and four joints. The imposed loads are generally transmitted by a collection of attached arches that form the joints to four supports. The construction of this arch begins from four corners and ends in the crown.

\section{Masonry Used in Mushkan Fire Temple}

The use of masonry like stone, brick, adobe, gypsum and so forth with different properties causes the creation of construction advantages and/or constraints. For instance, the congruence between the mortar and the adobe, brick and stone considerably contributes to the staticity of the building's load bearing components. And, since this integration can be created by the utilization of conforming mortar and constructional materials, the properties of the masonry gain importance in conjunction with the mortar's setting time in such a way that gypsum mortar as the most commonly applied mortar in arch-building possesses a particular stance due to the special conditions of the Iranian arches' construction and implementation.

In Islamic architecture in Iran and, especially, in the arched structures, use is most often made of the heavy constructional materials with the difference being that wood is applied as an auxiliary element for reinforcing the structure against tensile forces and also as a factor for resolving the building's staticity problems. Heavy masonry has also been used in Mushkan Fire Temple.

In the process of the building techniques' evolution and, particularly, in the vertical structures as well as horizontal structure and also arched structures, mortars always play an important role in rendering the formation of complex structures feasible. Mortar works as a sticky material. In the construction of the arched structures, the builders use various mortars. In Mushkan Fire Temple, use has been made of gypsum mortar and plaster of lime or ashes or sand.

High adhesion, rapid setting and the initial solidarity of gypsum have caused its widespread use in the implementation of the arched buildings. In fact, erecting an arched structure like dome, various kinds of arched roofs and vaults wherein wooden casts are not used entails the use of such materials. Moreover, lime mortars have also been applied in the construction of Mushkan Fire Temple. The importance of this mortar in the construction of the arched structures is mostly due to its use in the laying of the foundations. One of the most important lime mortars is a plaster made of lime and ash or sand that, though a little problematic in use, features a notable final strength.

\section{Conclusion}

Iranian architecture is replete with unique properties and attributes. The creative examples of the forerunners' innovations are seen in every single component and constituent element thereof. The components forming the 
structure have come about in conjunction with the time's necessities and they have undergone growth and perfection in the course of time. Arches and domes are elements of traditional architecture with a rich background going well beyond BC times. They have emerged, become prevalent and expanded in the architectural works and they have been transformed into the common structural component in the post-Islamic architectural periods. The Iranian architects have brought about diversities in the forms of their applications and created numerous examples like arch, vault, curve, dome and so forth and covered the curved part of a doorway by them.

It was with the establishment of Sassanid Dynasty that the Iranian culture and civilization was revitalized and the ground was set for the growth and development of various arts. Along with the continuation of the prior architectural designs and techniques, Sassanids' architecture witnessed the perfection of the previous designs and the genesis of the innovations as well as new techniques, components and elements. Amongst the most important accomplishments of this period is the construction of dome on a square substructure and the world's architecture is in debt to the Sassanids' architecture in this regard. Zoroastrianism was the Sassanid Era's formal creed and the buildings related to this religion possessed a lofty position. The main buildings of the temples were independent four-dome edifices underneath which fire has been burning and it has been visible for the believers in the course of the religious ceremonies from the four spans. There have also been complexes wherein fire was kept going in other occasions. Four-dome edifices or the very fire temples are amongst the most important religious buildings of Sassanid Era. They were laid on the foundation of four wide spans and they usually had four gates. The recognition of Sassanid Era's four-domes and their attribution to Sassanid era and determination of their uses as fire temples are amongst the problems faced in the investigation of the religious buildings from this period. Until before now, every building identified with mortar, rubble and plaster of line and ash was attributed to Sassanid Era. However, it can be possibly understood in further investigation that this architectural style has been still thriving during the early Islamic period. Sassanid Era's four-domes, known as fire temples, have a circumambulation hall in the periphery of the building and also a central hall wherein the fireplace is situated. The studied case, i.e. Mushkan Fire Temple, has all of the aforementioned components.

Along with the vast diversity of the masonry used in this period [rubble, carved stone, brick, adobe, clay, mud and gypsum and wood and so forth], the use of the available and vernacular masonry and skillful application of rubbles and turbid gypsum for the construction of various buildings are amongst the distinct features of this period's architecture. As for Mushkan Fire Temple, it can be stated that the use of stable masonry like stone, plaster of ash and lime and gypsum as well as the application of arches with large spans are amongst the most important reasons for the structural stability of this four-dome building.

\section{References}

[1] Azad, Mithra, [2005], “investigation of the Sassanid Era's buildings evolution into the religious buildings of the early Islamic centuries", MA dissertation, Tehran, Teacher Training University.

[2] Ashrafi, Roshanak, [2013], "Iranian dome and its position in Islamic architecture", accessible in http://www.islamicartz.com

[3] Tajvidi, Akbar, [1984], "continuation in Iranian architecture", v. 1, by the efforts of Asiyeh Javadi, Tehran, Mojarrad, pp. 11-25.

[4] Hejazi, Mehrdad and Mirghaderi, Rasoul, [2004], "seismic analysis of the Iranian domes", journal of technical faculty, v. 8 , no. 6 .

[5] Darya'ei, Touraj, [2009], "Iranshahr's counties", tr. Shahram Jalilian, Tehran, Tus.

[6] Dehkhoda, Ali Akbar, [1993], "Dehkhoda Dictionary", under the supervision of Mohammad Mo'ein and Sayed Ja'afar Shahidi, Tehran, Tehran University Press.

[7] Reuther, Oscar, [2008], "the history of Sassanid Era's architecture: an investigation of Iranian art", by the efforts of Arthur Pope and Phillips Akerman, Tehran, scientific and cultural, pp. 639-710.

[8] Shipman, Clarus, [2005], "basics of Sassanids' history", tr. Kaykavus Jahandari, Tehran, farzan.

[9] Zia'a Abadi, Arash, [2007], "Karbandi [formulating geometry], the birthplace of the space-frame structures", the $2^{\text {nd }}$ national conference on the space-frame structures", Tehran, Tehran University, Faculty of Architecture, fine arts campus.

[10] Godard, Andrea, [1992], "Iran's artworks", v. 3, tr. Abu AlHasan Sarvghad Moqaddam, Astan-e-Quds-e-Razavi's research foundation.

[11] Farshad, Professor Dr. Mahdi, [1997], "the engineering history in Iran", v. 3, Balkh Publication Institute affiliated with Neishabour Foundation.

[12] Moradi, Yusuf, [2009], "Mil Geh Four-Dome: a fire temple from Sassanid Period", archaeological studies, [1]: 155-183.

[13] Mardomi, Karim; Soheylifard, Mahdi and Agha Azizi Majid, [2015], "consistency of the structure and architecture in line with optimal siting of the supports by the use of genetic algorithm [case study: free-form covers designed based on Iranian knot geometry]", Naghsh-e-Jahan, no. 10.

[14] Mo'ein, Mohammad, [1984], "Persian dictionary", Tehran, Amir Kabir.

[15] Hashemi Zarjabadi, Hasan and Bahar, [2010], "four-dome of the house of ogre: a newly discovered fire temple from Sassanid Era", journal of Bagh-e-Nazar, 7 [15]: 79-92.

[16] Huff, Dietrich, [1987], "domes in Islamic architecture", trs. Keramatollah Afsar and Muhammad Yusuf Kiani, about Islamic period's Iranian architecture, by the efforts of Yusuf Kiani, University Jihad, pp. 397-414.

[17] Boyce, M., [1975], "On the Zoroastrian Temple Cult of Fire", JAOS 95, PP. 464- 465. 
[18] Huff. D, [1987], "Architecture II, Sassanian Period", Encyclopedia Iranica, vol. II, Routledge \& Kegan Paul, London and New York, pp. 329-334.

[19] Godard, A., 1938, "Les monuments du feu", Athar-e Iran, p. 12.

[20] Keall. E. J, [1989], “Ayvan [or Tagh]-Khosrow”, Encyclopedia Iranica, vol. III, Routledge \& Kegan Paul, London and New York, pp. 155-159.
[21] Neumann, R., Et Ali, [1965], Takht-i Suleiman und Zendan-i Suleiman, VorläufigerBerichtüber die- Ausgrabungen in den Jahre 1963 und 1964, AA 1965, pp. 621-623.

[22] Reuther, Oscar, [1939]. "Sasanian Architecture", in "A survey of Persian art", edited by Arthur Upham Pope, vol. [2] oxford university Press, pp. 493-578.

[23] Pope. A. U., [1933], "A Sasanian Garden Palace", The Art Bulletin, vol. 15, no. 1, pp. 75-85 